\title{
Wittgenstein's Ethnological Approach to Philosophy
}

\author{
CHRISTOPH DURT, BERKELEY
}

\section{An ethnological approach to philosophy?}

On July 2, 1940, Wittgenstein wrote a remark that was later published in Culture and Value:

If we use the ethnological approach does that mean we are saying philosophy is ethnology? No, it only means we are taking up our position far outside, in order to see the things more objectively. (Wittgenstein 1998, 45e)

This citation on its own opens up more questions than it answers. Wittgenstein implies that in philosophy he uses a perspective that allows for a »more « objective view. But what exactly does he mean by »the ethnological approach «? Why does it go beyond ethnology? Why is it an approach to philosophy? What are »the things « he refers to? Why did he underline the definite article with a wavy line? And why does the ethnological approach allow for seeing things »more objectively«? Culture and Value is a highly unsystematic collection of remarks and neither this citation alone nor its context completely illuminates what Wittgenstein means. From his previous remark on the same day it is merely clear that the »ethnological approach « stands in contrast to the »causal approach « (Wittgenstein 1998, $45 \mathrm{e})$ :

What is insidious about the causal approach is that it leads one to say: that's how it has to happen «. Whereas one ought to say: It may have happened like that, \& in many other ways.

The causal approach is misleading because it suggests that its description is the only possible one. The present tense »how it has to happen « indicates that the causal approach applies to all happenings alike, while with the past tense in »it may have happened like that « Wittgenstein concentrates on one event. He does not regard his description as revealing some necessary truth but rather as providing a comparison and explicitly mentions the possibility of other descriptions. 
But what exactly does Wittgenstein mean by »the causal approach « and $»$ the ethnological approach «? Wittgenstein provides no detailed definition and I do not claim that there is only one possible answer. But I do think that we can make sense of the »ethnological approach « to philosophy, realize that it is found throughout the whole of his later work, and understand why he made such broad use of it.

An important part of this is his seemingly ethnological preoccupation with Frazer's magisterial treatise, one that began no later than 1931 and probably lasted over 20 years. ${ }^{1}$ Sir James Frazer's The Golden Bough: A Study in Comparative Religion represents a milestone in the development of anthropology and ethnology, and also had a significant impact on other sciences as well as on literature. For philosophy, however, it initially does not appear to be of great interest, and it seems surprising that Wittgenstein spent such a considerable amount of time and thought on it. One might speculate that the reason for Wittgenstein's extensive and intensive occupation with Frazer's Golden Bough was simply that he expected to learn something about other cultures: About the ordinary and the extraordinary behavior of other people, their rites and customs, their art, their myths, their world-view and the "pictures « they apply when interacting with and apprehending the world. ${ }^{2}$ But Wittgenstein's harsh rejection of Frazer's explanations casts doubt on this speculation. Wittgenstein disparages Frazer's explanations as »crude « $(R F G B, 131)$, as expressions of a »narrow spiritual life « $(R F G B, 125)$, and accuses Frazer himself of being much more »savage than most of his savages « $(R F G B, 131)$. Such disparaging remarks indicate that Wittgenstein did not believe that Frazer succeeded in explaining

\footnotetext{
${ }^{1}$ Wittgenstein had long wanted to obtain The Golden Bough and started reading it in its abridged version in 1931 (cp. Rhees 1984, 119). He repeatedly revised some of his remarks and included them in his PI and other works - this can easily be retraced using the electronic Bergen Edition (Wittgenstein 2000).

${ }^{2}$ I will use the term $>$ culture $<$ in its broad sense, which includes not only >high culture< but also both common behavioural patterns and views (e.g. >myths $<$, > world-picture $<$ and >pictures $<$ ), in addition to much more. I do not think that culture is a rigid fundament of meaning, or that cultures are homogenous, or that one can sharply distinguish one culture from another. The lack of a strict definition of the term $>$ culture $<$, however, does not mean it is useless.

I did not use Wittgenstein's term »forms of life « because I did not want to introduce a term that could easily be misinterpreted as a technical term. >Culture< in the broad sense as it is used in more recent discussions might be more appropriate to express the broad interrelatedness of language games, behavioural patterns and view. Unfortunately, here there is not enough space to discuss these terms extensively.
} 
the customs. I will argue the reverse: Wittgenstein continued to read Frazer not to learn more about other languages and cultures, but about something else inadvertently revealed by Frazer's explanations, namely the influence of his own language and culture on the explanation of other cultures. By considering such influences, Wittgenstein did not attempt to solve problems concerning the ethnological understanding of different cultures and languages, but rather reflected on our own language and culture and their influence on philosophy.

Thinking about (real or imagined) other cultures might fulfill several purposes for philosophy. For instance, it might show the dependence of language on normal use and the regular rule-following of the members of a culture. It can provide hints on what is involved in understanding the behaviors and concepts of different cultures and in turn elucidate what is involved in understanding the behaviors and concepts of one's own culture. It could be used to imagine some concept in a different context, allowing for a clearer understanding of the dimensions of that concept. It might connect fundamentally different concepts or at least tell how they are possible. These connections might also indicate what necessarily belongs to the concept and what does not. Besides these there may be many more possible reasons for philosophy to think about other cultures. However, given my very limited space here, I will concentrate on the approach to philosophy that Wittgenstein developed from thinking about ethnological investigations of different cultures. While comparisons to philosophers pursuing related ideas promise further insights, I will restrict this essay to the context of Wittgenstein's work only.

\section{Wittgenstein's critique of the causal approach to ethnology}

Wittgenstein defines the ethnological approach as being in contrast to the causal approach. What he means by the latter can best be seen when we compare some of his later writings on philosophical description to his remarks on Frazer's way of explaining rites, customs and behaviors of past cultures and their continuance to the present. Following Wittgenstein, Frazer does not apply the proper ethnological approach to ethnological questions, but the causal approach. The latter has two sides. Wittgenstein's critique on Frazer's causal approach is harsh because he argues that both sides completely miss what Wittgenstein thinks is essential for ethnology.

The one side is characterized by the question of the appropriate method for ethnological investigations. Frazer applies the scientific method of stat- 
ing hypotheses and then sets out to confirm or disprove them. Frazer's explanations at a first glance seem like empirical science. Wittgenstein reveals that in fact these explanations often do not result from scientific method but from sensationalism and subjective biases. His main critique, however, is not to Frazer's way of hypothesizing, but to the fact that Frazer puts forward hypotheses to be proved or disproved like empirical hypotheses in the positive sciences. Frazer adopts a positivistic approach in the tradition of Auguste Comte, who thought that all of sociology's questions are open to strict empirical investigation. Wittgenstein in contrast thinks that the methods of empirical science are not equally applicable to ethnology.

This disagreement has its source in a disagreement about how ethnology can sensibly describe the customs to be investigated. Frazer's explanations are not only misleading because he puts forward hypothetical assumptions, but furthermore because these concern the cause of the customs he is trying to explain. He looks for what caused them - their historical origin - and continues to pursue its development into the present. One example is the rain dance. Frazer tries to trace the custom back to the original »error «, the misunderstanding that caused the superstition, and asks why it was passed down over centuries. Wittgenstein does not necessarily think the origin is irrelevant. However, he points out that the original belief might have been lost or became unimportant to the practitioners and that at different times the custom might fulfill different purposes. Even if people once thought that the rain dance caused rain (and some might still think so), this is not necessarily the reason for why it is practiced today. Following Wittgenstein, ethnology can easily misinterpret customs if it is merely looking for their original cause.

The other side of Frazer's causal approach concerns the question of what the different customs possibly could mean: their significance for their practitioners, their role and function for the life of their practitioners and the context in which they are practiced, among other features. Frazer is not only trying to use the scientific method himself, but he also believes all customs are expressions of some form of scientific reasoning. He applies a particular understanding of evolutionary theory to ethnology when he assumes that all customs of all cultures at all times can be fitted into a developing scheme in which more complex habits evolve from primitive ones. According to Frazer they all fall under one of these three main categories: »magic «, »religion« and »science «. Magic is the most primitive form, religion is somewhat more sophisticated, while science is the most sophisticated of all. Here again his account is reminiscent of Comte's positivism 
with the distinction between the »theological «, the »metaphysical« and the »positive « phases.

While Frazer believes in evolutionary progress, he does not subscribe to the reductionistic supposition that only material, biological or sexual aspects play a role in the progress of culture and that therefore the concepts of those who practice its customs are negligible. He is very interested in what the practitioners associate with the custom. Also he considers other cultures' languages for he believes that the myths of cultures are expressed in the words they use.

However, he has a simplistic understanding of what the other people might associate with the custom. He takes all three main levels of customs - »magic«, »religion « and »science« - to follow the same scheme: They provide ways of dealing with hypotheses concerning the causal interrelations in the world; they are all nothing but more or less primitive science. The practitioners of the customs believe they help them to dominate some forces in the world because they are a result of their hypothesizing. Frazer thus assumes that the customs always indicate some (often insufficient) scientific thinking. His approach is pejoratively ethnocentric because he tries to fit all customs of all cultures at all times into a simplistic scheme that doesn't admit the possibility of other ways of thinking than his own.

An example of Frazer's scheme to interpret every custom as following some kind of scientific reasoning is again the rain dance. Frazer considers it to be a crude method of producing rain. The dancers believe that their dance will somehow cause it to rain and they want it to rain, therefore they take part in a rain dance. Eventually it does rain, and so, according to Frazer, the hypothesis is confirmed and the false belief is passed down from generation to generation - possibly over centuries.

Wittgenstein, in contrast, thinks it unlikely that the error will go unnoticed for a lengthy period of time, and wonders why the rain dance takes place at the beginning of the rainy season when it will rain anyway, and not during the dry season when the rain is most needed. He does not necessarily consider the rain dance to be a primitive form of science following the hypothesis that it causes rain, but writes that it could also be an expression of a »wish « $(R F G B, 125)$. Analogously, kissing the picture of a beloved one in the English culture of Frazer's time does not necessarily express the belief in some mystical causal power. Wittgenstein accepts that the customs on occasion might be based on some hypotheses the practitioners have, but he thinks that often they indicate a different significance to the practitioners. 
Indeed, the practitioners might not associate any special reason to the custom. They might participate in it because it is what they are used to do or because it is what they are supposed to do. Ethnology has to consider the possibility that customs are not always an expression of conscious reasoning. The practitioners might even deceive themselves about their >actual< reasons and the custom might be better described with regards to e.g. the function it fulfills for something else. These different possibilities do not imply that the practitioners' concept of their custom is superfluous, but support the claim that there is not one scheme all customs follow.

\section{Wittgenstein's critique of the causal approach to philosophy}

Similarly to ethnology, philosophy could be tempted to pursue the causal approach - both in terms of its method and in terms of what concepts could mean. With regards to philosophy's method, it could be tempting to borrow the method of positive sciences and postulate »hypothetical entities « (PI, $\S 109)$ in addition to phenomena and then try to prove or disprove them. Such hypothetical entities might be causes (PI, §466), natural facts (PI, $\S 89)$, or causal connections (PI, §89).

Some interpreters think that Wittgenstein himself is providing merely empirical explanations since sometimes he describes the linguistic and psychological sources of some philosophical mistakes. While it is true that Wittgenstein occasionally describes causes in order to explain how one could come up with erroneous ways of thinking, he explicitly says he is doing more than describing causal connections (cp. PI, 198).

Echoing his critique on Frazer's attempt to find the original cause of some custom, Wittgenstein speaks against attempts of founding philosophy in original causes. We can give reasons for our way of following a rule and the question »How can I follow a rule? « is either a question for causes or for justification $(P I, \S 217)$. Wittgenstein admits that $»$ justification through experience has its end « $(P I, \S 485)$, but this end is not an original cause. Rather, Wittgenstein compares the end to a »rock« that bends back the »spade « $(P I, \S 217)$. The ground of our rule-following consists of the manners of behavior and common views of a culture (in my definition of $>$ culture < in footnote 2). It is not a last cause or unchangeable fundament, but can be compared to the bed of a river. The riverbed changes with time (some sand moves quicker and some rocks only imperceptibly), but we can distinguish it from the water that runs through it (cp. Wittgenstein 2000, Item 174, 22r; or On Certainty, §94-99). 
Following Wittgenstein, the postulation of hypothetical entities can easily lead to misinterpretations of one's own culture's concepts. To better understand them, we have to clarify how they are used: We have to describe their function, their significance for the people who use them, the context they stand in, etc. Philosophy's task is not to solve empirical problems $(P I, \S 109)$ but to clarify concepts: »our problem is not a causal but a conceptual one « $(P I, 203 \mathrm{e})$. The conceptual clarifications are neither empirical in the sense of the positive sciences nor are they independent of the actual use of the concepts.

With regards to what concepts possibly could mean - their significance for their users, their role and function for the life of their users and the context in which they are used, among other features ${ }^{3}$ - some philosophers think language always works the same way. They might believe e.g. that all we do with words is name things, that words stand for persons or objects in the world, mental objects, feelings, etc. The later Wittgenstein writes he himself once succumbed to an error of this kind. In sentence 4.5 in Wittgenstein's Tractatus he introduces what he then took to be the logical form of every proposition: »... Such and such is the case «. Wittgenstein later on rejects such a »formal unity« (PI, §108), which seems to comprise both language and the world (cp. PI, §114) and calls the latter assumption »nonsense « $(P I, \S 134)$. »Such and such is the case « is a general form only because it in itself is already a meaningful sentence of an already existent language (cp. PI, §134). It misleadingly seems to provide a criterion for determining what a proposition is, but really is dependent on ordinary language. ${ }^{4}$

To understand the sentence in question we thus have to see how it is ordinarily used. This will involve giving examples and inductively applying them to other cases (cp. PI, §135). We have to understand the rules with which sentences can be built. Understanding the rules for the use of a concept includes understanding the application of the rules, the latter not being self-evident.

\footnotetext{
${ }^{3}$ That we >mean something < with concepts, of course, does not imply there has to be a $>$ thing < the concepts refer to. Instead of searching for some hidden >meaning<, Wittgenstein looks at how the concepts are used.

${ }^{4}$ With >ordinary< I do not vindicate the myth of an original myth- and theory-free language. On the contrary I believe that many philosophical problems already arise from what is suggested by ordinary language. Wittgenstein writes that the »main source of our lack of understanding « is the lack of perspicuity of grammar (PI, §122). However, one can still distinguish ordinary from special use and point out that the latter is dependent on the former.
} 
Analogous to the many possible significances, roles and contexts of a custom (among other features), there are as well many possible ways to use words. Wittgenstein compares the understanding of the concept of $>$ sentence $<$ to understanding the concept of $>$ game< $(P I, \S 135)$. As there can be many different games, there also can be many different sentences. Wittgenstein's term »language game « expresses that there are many ways to use language that are not reducible to the same type.

Wittgenstein's critique of the causal approach in ethnology is mirrored in his critique of positivistic approaches to philosophy. Both ethnology and philosophy should not hypothetically explain facts by providing causes and both should not simplistically assume all customs or concepts follow a certain scheme. Since the causal approach disregards these requirements, it is inapt for both ethnology and philosophy.

\section{Describing and explaining}

To steer clear of the pitfalls of the causal approach both with regards to method and with regards to what the customs or concepts possibly can mean, the ethnological approach has to be >open< to the possibility of different kinds of customs and language games. However, this specification by itself is not enough, as it leaves unclear how exactly we can be >open<.

Concerning method, Wittgenstein in many places seems to promote a purely descriptive approach. He writes that only the hypothesis Frazer puts forward »seems to give the matter depth for the first time « $(R F G B, 143)$. This depth is merely apparent, because Frazer does not describe the function of the customs, their role in the life of their practitioners, their significance for their practitioners etc., but rather ascribes them a certain function, role and significance. Wittgenstein in contrast thinks that $\gg \ldots$ one must only correctly piece together what one knows...« $(R F G B, 121)$ and states:

Here one can only describe and say: this is what human life is like. $(R F G B, 121)$

This remark on Frazer's Golden Bough echoes even stronger in Wittgenstein's PI:

We must do away with all explanation, and description alone must take its place. $(P I, \S 109)$ 
Prima facie it looks like Wittgenstein is demanding to replace evaluative explanation by neutral description. This would mean that Wittgenstein himself pursues a positivistic approach. However, to what extend can the description be neutral and what kind of explanation is it supposed to replace?

Frazer is writing in a suggestively grim tone (cp. $R F G B, 121)$ and negatively judges the »many strange foreign lands, with strange foreign peoples, and still stranger customs « (Frazer 1922, chapter I, part 3) even before he explains them. His explanations thus entail biased evaluations. Wittgenstein's investigations, in contrast, are not evaluative in this sense, even though they might eventually lead to evaluative judgments. However, his description of the different customs is not an unsystematic concatenation of observations but structured by showing commonalities between different customs. Even description in this weak sense is evaluative since the commonalities shown would exclude others and thereby favor a certain view over other views. Wittgenstein's descriptions are evaluative in the sense that they aim to eradicate certain >misunderstandings $<$, and in that they provide alternative pictures. With »description « Wittgenstein does not mean $>$ merely descriptive $<$ in contrast to $>$ evaluative $<$.

With the contrasting term »explanation « Wittgenstein denotes something we ordinarily would regard to be a special case of explanation. In the sentence before the latter citation from his $P I$, he turns against hypothesizing. For him, »Every explanation is after all a hypothesis « $(R F G B, 123)$. The kind of explanation he rejects comprises explanations of the causal approach in the senses shown above, i.e. explanations that put forward hypothetical causes and assume everything can be explained in the same way. Wittgenstein argues against ascribing an imagined »depth « by drawing on misleading references, but this does not mean he is against drawing any connections to one's own language and culture.

Concerning the question of how this description can be pursued, Wittgenstein is sometimes interpreted as a pure relativist claiming that in our language we cannot describe the behavior or concepts of a different culture. Other interpreters object that Wittgenstein speaks of a »common human behavior « $(P I, \S 206)$ and take the latter to be the universal ground of communication. ${ }^{5}$ In the German-speaking world there has been extensive discussion around »common human behavior « which I pursued at the Wittgenstein Symposium in Passau (Durt 2005a). For a sensitive interpretation it is crucial not to assume Wittgenstein's thought must fit into sim-

\footnotetext{
${ }^{5}$ References to both types of interpretation can be found in Durt 2005a.
} 
plistic categories. He does not need to claim some behaviors are universal or that there is an objective meaning in a positivistic sense in order to be able to differentiate more from less problematic concepts. Wittgenstein distinguishes between concepts such as »ghost «, »shade «, »soul« and »spirit« and concepts such as >head< (as a body part) and >fall off< (as the motion of a body part). The former terms can more easily mislead because they depend more on certain myths and pictures Frazer inadvertently uses.

As I explained in my presentation at the Kirchberg Wittgenstein Symposium last year (Durt 2005b), ${ }^{6}$ Frazer's explanations of different cultures also provide examples of the dependencies of language on the myths, pictures and worldviews of one's own language and culture. Frazer extensively uses myth-laden terms such as »soul «, and thereby misleadingly ascribes conceptions from his culture onto other cultures. This is a problem for all terms connected to the myths, pictures and worldviews of our own culture, as they make us prone to formulating erroneous views on language and culture, both with respect to other languages and cultures as well as within our own. Wittgenstein writes that »an entire mythology is stored within our language « $(R F G B, 133)$, which might lead to »temptations «, »seductions « and »bewitchments« (e.g. PI, §374, §194, §109) that distort our understanding. However, does this mean we should dispense with terms connected to our myths, pictures, and world-views? Should we just describe what we see on the surface in order not to be misled by some apparent deeper connection?

\section{Wittgenstein's approach to other languages and cultures}

While for Wittgenstein it is important to show commonalities between the different customs, he also writes that something more is needed to »give the account its depth $\ll$ :

Besides these similarities, what seems to me to be most striking is the dissimilarity of all these rites. It is a multiplicity of faces with common features which continually emerges here and there. And one would like to draw lines connecting these common ingredients. But then one Part of our account would still be missing, namely, that which brings this picture into connection with our own feelings and thoughts. This Part gives the account its depth. $(R F G B, 143)$

${ }^{6}$ The full paper and its amended PowerPoint presentation can be accessed at www.durt.info. Also available for download is the PowerPoint presentation relating to this paper. 
The »multiplicity of faces with common features which continually emerges here and there « evokes Wittgenstein's concept of »family resemblance«. Finding »family resemblances« within a different culture is important for connecting seemingly disparate parts. However, this is not enough as the description would continue to be superficial, and would be little more than an enumeration of the connections that emerge superficially like patterns in a void. To give the description depth we must find meaningful connections that relate to our feelings and thoughts. We have to find family resemblances not merely within their customs but also between their customs and ours. Not all family resemblances we immediately find will withstand subsequent scrutiny. But we should not stop searching for them, since only the connections between our patterns of behavior and theirs can give the description a profound sense.

Wittgenstein gives many examples of how this search for connections might be pursued and what peculiarities it leads to. In considering different cultures, Wittgenstein investigated how we can differentiate language games. One example is the different »form of life « with its unusual way of playing chess that he describes in $\$ 200$ of his PI. The chess players yell and stamp their feet in a manner that could be translated into the game we know as chess. Wittgenstein writes:

[...] now imagine a game of chess translated according to certain rules into a series of actions which we do not ordinarily associate with a game - say into yells and stamping of feet. And now suppose those two people to yell and stamp instead of playing the form of chess that we are used to; and this in such a way that their procedure is translatable by suitable rules into a game of chess. Should we still be inclined to say they were playing a game? What right would one have to say so? (PI, $\S 200)$

Wittgenstein is able to ask the question of whether their behavior can be called a >game< only because there is translatability from their behavior to ours. Such translatability, however, could be argued to exist with respect to very remote forms of behavior. The movements of a crowd of people, for example, using the respective rules for translation, could also be described as a chess game. But we would not therefore say >they are playing<. The translatability of some forms of behavior such as yelling or the stamping of feet is not enough to answer the question of whether we should call it a game. So what is missing?

The answer to this question lies in the other forms of behaviors enacted by those yelling and stamping their feet: Do they act like players, e.g. do 
they think about their next move? Are there winners and losers? What would they say they are doing? We can ask hundreds of questions like these to try and determine whether some behavior constitutes the playing of a game. Not every single one has to be answered with a >yes<; instead we will be satisfied in concluding they are playing a game when a significant component of their behavior resembles important features of our game playing behavior.

This example suggests that in order to understand some behavior in an unknown culture we have to find connections between their behavior and our behavior that together are strong enough to indicate a family resemblance to our concepts. As there may be various meaningful connections, we should not automatically assume that they are all of a certain kind. But we can look into how to describe the family resemblances without presupposing their nature.

Wittgenstein calls the description that allows for seeing the family resemblances »perspicuous representation« (»Übersichtliche Darstellung «): ${ }^{7}$

The concept of perspicuous representation is of fundamental importance for us. It denotes the form of our representation, the way we see things. (A kind of $>$ Worldview $<$ as it is apparently typical of our time. Spengler.)

This perspicuous representation brings about the understanding which consists precisely in the fact that we »see the connections«. Hence the importance of finding connecting links. $(R F G B, 133)$

The perspicuous representation shows the connections between different ways of behavior in a clear manner. This includes describing their concepts since to understand their behavior we also have to understand what they attribute to it, and for that we have to consider the concepts they use.

Different concepts can be perspicuously described in the same way: By finding connecting links between them and between them and one's own language. Some of the connections to be found are obvious, while others have to be strenuously sought or invented. Perspicuous representation does not explain what the ways of behavior or concepts >really< mean according to some presupposed scheme, but it enables us to see how they are connected to each other. This way, very different concepts can be linked. Wittgenstein in his Remarks on the Foundations of Mathematics even considers connections to different concepts of counting and calculating. Such

\footnotetext{
${ }^{7}$ While Wittgenstein borrows some of his ideas concerning the Übersichtliche Darstellung from Spengler, he criticizes Spengler for his »dogmatism« (cp. Wittgenstein 1998, 30f).
} 
links can allow for understanding the possibility of other concepts of what seemed to be a logical necessity (cp. Stroud 1987).

\section{A »more objective« approach to one's own language and culture}

While Wittgenstein worked out the concept of perspicuous representation specifically with respect to Frazer, it can be applied to other cultures and languages as well as to our own. With only slight revisions, the notion can be found in Wittgenstein's reflections on philosophical methods in the PI:

[...] A perspicuous representation produces just that understanding which consists in $>$ seeing connexions $<$. Hence the importance of finding and inventing intermediate cases.

The concept of a perspicuous representation is of fundamental significance for us. It earmarks the form of account we give, the way we look at things. (Is this a $>$ Weltanschauung $<$ ? $)(P I, \S 122)$

In the German original the citations are even more similar. The only major differences are that the order of the sentences is reversed and the reference to Spengler in the $R F G B$ is replaced by a question in the $P I$. The terms »connecting links « and »intermediate cases « are two translations of the same term. While both translations emphasize correct aspects (e.g. that their position is in between, that they connect, that they provide examples), I will use the term »Zwischenglieder « from the German original to accord with the fact that the same term is used in the RFGB and in the PI.

Most significantly, in the RFGB Wittgenstein does not speak of >inventing Z Zwischenglieder. However, he subsequently gives the example of an ellipse that is gradually converted into a circle. The connecting intermediate cases are not used to claim that the circle historically evolved from an ellipse. Rather, they show a »formal« connection between ellipse and circle that makes their relation visible. Such »hypothetical « Zwischenglieder can just as well be found as invented. We can therefore assume that at the time of writing the RFGB Wittgenstein already considered Zwischenglieder in this way.

To explain historical developments it would be necessary to show that Zwischenglieder factually existed. However, even if this were our final aim, we would first of all need to consider what has to be connected, i.e. the function, role and significance of different concepts and customs. To do so we would need to find family resemblances. When searching for the latter it makes no difference whether the Zwischenglieder are found or in- 
vented. What is important is that they help highlight the connections within an individual concept, view, or behavioral pattern and/or between the concepts, views and behavioral patterns.

Does Wittgenstein himself thus presuppose with his perspicuous representation the positivistic assumption that there is an objective explanation independent of our culture? The term »Übersichtliche Darstellung « might suggest this, as the two word parts >über< and >sicht< in the German original (English: >over $<$ and >view $<$, together: >survey $<$ ) can be interpreted as meaning a view of cultures from above. Accordingly, in the English version of Philosophical Remarks »Übersichtliche Darstellung « is translated as a »bird's eye view « (Wittgenstein 1975, I §1). Where possible, the view from above appears to be the best position from which to »see connexions «. But the translation »bird's eye view « is misleading and has often been criticized. ${ }^{8}$ Wittgenstein does not try to give an objective description independent of language and its underlying views and behavior patterns. Instead, he looks for connections to his own language and culture. Wittgenstein does not think it absurd to ask if his concept of perspicuous representation is a world-view (which usually entails beliefs, pictures or views peculiar to a group of people). If it is a world-view, it is so because it replaces the view of the world as a realm of objectively describable causes. But it is not a world-view in that it would limit itself to one certain perspective.

The philosopher who uses perspicuous representation is describing his or her own language and culture in a similar manner to the ethnologist who describes a different language and culture. The perspicuous representation is the kind of description that is entailed by the ethnological approach. Considering its objectivity might therefore make clearer what Wittgenstein means with his claim in the first citation of this essay that by using the ethnological approach we are »taking up our position far outside, in order to see the things more objectively «. Wittgenstein underlined the definite article with a wavy line in order to indicate his doubt concerning its correctness. He does not wish to say that there is a given set of objects (>the things $<$ ) that is independent of our recognizing them. For the same reason he does not speak of >seeing things objectively<. Instead he uses the expression »more objectively«. In the German original this is expressed by only one word (»objektiver«), thus both English words are written in italics. If Wittgenstein had been writing in English, he might well have written

${ }^{8}$ For example, by Hacker, who introduced instead the term »surview « (Hacker 1986, 151ff). 
»more objectively « to emphasize the point that there is not one single objective approach (compare e.g. PI, §133) that can be used, but instead a more objective approach. This more objective approach is what Wittgenstein calls »the ethnological approach «.

It is more objective in the sense that it is less prone to be misled by scientific and other preconceptions or by the prejudices of one language or culture, for two reasons. The first is that it does not presuppose a given method such as the search for causes, and does not assume that all customs and concepts must be of a certain kind, as is entailed by the causal approach. The second reason is that the ethnological approach allows meaningful connections to become visible that were previously invisible in the views suggested by one's language and culture.

The Zwischenglieder are links between (»zwischen «) the different concepts and patterns of behavior. Their difference is not dissolved, lifted, neutralized or compensated in the dialectical sense. The perspectives entailed by the different concepts and patterns of behavior are not merged into an all-encompassing picture; Wittgenstein does not attempt to abolish either perspective. Rather, he leaves »everything as it is « $(P I, \S 124)$ and merely highlights the links between the different behaviors and customs. The understanding consists just in >seeing connections $<$.

Wittgenstein's view is not completely objective as it is not free from all suggestions or even »myths «, »temptations « »seductions « and »bewitchments « pertaining to one's own language and culture. On the contrary: they are necessary for finding the connections to different concepts and customs. Under the ethnological approach, however, one's own concepts do not lead to incorrect suppositions but are used to more clearly see the connections. Because it is in this sense more objective, Wittgenstein used the ethnological approach to philosophy.

Unfortunately, in this paper I could only hint at what Wittgenstein's ethnological approach amounts to, how it connects to the concepts Zwischenglieder and Übersichtliche Darstellung, and what role it plays in his philosophy. Despite this, I hope to have shown that the ethnological approach plays a fundamental role in Wittgenstein's philosophy, and that more detailed analysis would prove worthwhile. 


\section{REFERENCES}

Durt, C. 2005a „Wittgensteins interkulturelle Perspektive: auf der Suche nach gemeinsamen Handlungsweisen.", in W. Lütterfelds, T. Mohrs \& Djavid Salehi (eds.), Wahr oder Tolerant: Religiöse Sprachspiele und die Problematik ihrer globalen Koexistenz (Wittgenstein-Studien 11), Frankfurt a.M.: Peter Lang.

Durt, C. 2005b "Wittgenstein on the possibility of philosophy: The importance of an intercultural approach" in F. Stadler \& M. Stöltzner (eds.), Time and history: Papers of the 28th International Wittgenstein Symposium, Kirchberg: Austrian Ludwig Wittgenstein Soc.

Frazer, Sir, J.G. 1922 The Golden Bough: A Study in Magic und Religion, in Gutenberg-Projekt, EText-No. 3623, http://www.gutenberg.net/etext/3623. Last actualized 2003-01-01, downloaded 2004-01-30. [A further version can be found in http://www.sacred-texts.com/pag/frazer]

Hacker, P.M.S. 1986 Insight and Illusion, Oxford: Clarendon.

Rhees, R. (ed.) 1984 Recollections of Wittgenstein, Oxford: University Press.

Stroud, B. 1987 "Wittgenstein and Logical Necessity", in P. Moser (ed.), A priori Knowledge, New York: Oxford University Press.

Wittgenstein, L. 1967a Philosophische Untersuchungen: Philosophical Investigations, German-English Edition, ed. by G.E.M. Anscombe und R. Rhees, Oxford: Blackwell.

- 1975 Philosophical Remarks, ed. by R. Rhees. Oxford: Blackwell.

- 1993 "Bemerkungen über Frazers Golden Bough: Remarks on Frazers Golden Bough", in idem Philosophical Occasions: 1912-1915, German-English Edition, ed. by J. Klagge \& A. Nordmann, Indianapolis \& Cambridge: Hacket.

- 1998 Vermischte Bemerkungen: Eine Auswahl aus dem Nachlass. / Culture and Value: A Selection from the Posthumous Remains, German-English Edition, ed. by G.H. von Wright. Oxford: Blackwell.

- 2000 Wittgenstein's Nachlass: The Bergen Electronic Edition. Oxford University Press. 